\title{
Solutions of boundary value problems on extended-Branciari $b$-distance
}

\author{
Thabet Abdeljawad ${ }^{1,2,3^{*}}$, Erdal Karapınar ${ }^{2,4^{*}}$, Sumati Kumari Panda ${ }^{5}$ and Nabil Mlaiki
}

\begin{tabular}{l}
\hline${ }^{*}$ Correspondence: \\
tabdeljawad@psu.edu.sa; \\
erdalkarapinar@yahoo.com \\
'Department of Mathematics and \\
General Sciences, Prince Sultan \\
University, Riyadh, Saudi Arabia \\
2Department of Medical Research, \\
China Medical University Hospital, \\
China Medical University, Taichung, \\
Taiwan \\
Full list of author information is \\
available at the end of the article
\end{tabular}

available at the end of the article

\begin{abstract}
In this paper, we consider a new distance structure, extended Branciari b-distance, to combine and unify several distance notions and obtain fixed point results that cover several existing ones in the corresponding literature. As an application of our obtained result, we present a solution for a fourth-order differential equation boundary value problem.
\end{abstract}

MSC: $47 \mathrm{H} 10 ; 54 \mathrm{H} 25 ; 65 \mathrm{~L} 05 ; 45 \mathrm{~J} 05$

Keywords: An extended-Branciari b-distance; $\Theta$-Branciari contraction; Ćirić-Reich-Rus type $\Theta$-Branciari contraction and interpolative- $\Theta$-Branciari contraction; Fourth-order differential equation boundary value problem

\section{Introduction}

The distance notion is as old as the history of finding the writing. On the other hand, the abstract formulation of the notion of distance is relatively new. It was formulated by Fréchet in 1905 for the distance of sets. In the setting of points, it was discovered by Pompeiu and Hausdorff in 1914 under the name of metric. After that it has been improved, generalized, and extended in several ways. Among them, we mention the distance that was proposed by Branciari.

Definition 1 (See e.g. [1]) Let $\mathcal{S}$ be a non-empty set, and let $b: \mathcal{S} \times \mathcal{S} \rightarrow[0, \infty)$ such that, for all $x, y \in \mathcal{S}$ and all $u \neq v \in \mathcal{S} \backslash\{x, y\}$,
(b1) $\quad b(x, y)=0 \quad$ if and only if $\quad x=y \quad$ (self-distance/indistancy),
(b2) $\quad b(x, y)=b(y, x) \quad$ (symmetry)
(b3) $\quad b(x, y) \leq b(x, u)+b(u, v)+b(v, y) \quad$ (quadrilateral inequality)

In this case, the map $b$ is called a Branciari distance. The pair $(\mathcal{S}, b)$ is called a Branciari distance space and abbreviated as "BDS".

In many sources it was called "generalized metric space" or "rectangular metric space", but these names do not reflect and indicate the notion (see e.g. [2-19]). Indeed, "Branciari

(c) The Author(s) 2020. This article is licensed under a Creative Commons Attribution 4.0 International License, which permits use, sharing, adaptation, distribution and reproduction in any medium or format, as long as you give appropriate credit to the original author(s) and the source, provide a link to the Creative Commons licence, and indicate if changes were made. The images or other third party material in this article are included in the article's Creative Commons licence, unless indicated otherwise in a credit line to the material. If material is not included in the article's Creative Commons licence and your intended use is not permitted by statutory regulation or exceeds the permitted use, you will need to obtain permission directly from the copyright holder. To view a copy of this licence, visit http://creativecommons.org/licenses/by/4.0/. 
distance" cannot reduce to the standard metric. Further, general topological properties are not compatible. That is why we prefer to use Branciari distance space. For a recent extension of such spaces, we refer to [20,21] and [22-28].

Recently, in [29] a concept of $\Theta$-contraction was proposed to extend some fixed point theorems in the context of Branciari distance space. For the sake of completeness, we recollect the notion of $\Theta$-contraction here:

Let $\Theta$ be the set of all non-decreasing, continuous functions $\theta:(0, \infty) \rightarrow(1, \infty)$ satisfying the following conditions:

(†) for each sequence $\left\{s_{n}\right\} \subset(0, \infty), \lim _{n \rightarrow \infty} \theta\left(s_{n}\right)=1$ if and only if $\lim _{n \rightarrow \infty} s_{n}=0^{+}$;

(\$) there exist $q \in(0,1)$ and $\ell \in(0, \infty]$ such that $\lim _{s \rightarrow 0^{+}} \frac{\theta(s)-1}{s^{q}}=\ell$.

This definition has been refined and applied to several fixed point results, see e.g. [8$12,20,21,30-48]$.

On the other hand, we recall the notion of extended $b$-metric space (simply, $d_{e}$-metric space) introduced by Kamran et al. [32], which is the most general form of the concept of metric. We recollect the definition as well.

Definition 2 ([32]) For a non-empty set $S$ and a mapping $\omega: S \times S \rightarrow[1, \infty)$, we say that a function $\rho_{e}: S \times S \rightarrow[0, \infty)$ is called an extended $b$-metric (in short, $\rho_{e}$-metric) if it satisfies:

(i) $\rho_{e}(x, y)=0$ if and only if $x=y$;

(ii) $\rho_{e}(x, y)=\rho_{e}(y, x)$;

(iii) $\rho_{e}(x, y) \leq \omega(x, y)\left[\rho_{e}(x, z)+\rho_{e}(z, y)\right]$

for all $x, y, z \in S$. The symbol $\left(X, \rho_{e}\right)$ denotes a $\rho_{e}$-metric space.

We shall combine these two notions, extended b-metric and Branciari distance, under the name of an extended Branciari b-distance space by the following definition.

Definition 3 For a non-empty set $S$ and a mapping $\omega: S \times S \rightarrow[1, \infty)$, we say that a function $d_{e}: S \times S \rightarrow[0, \infty)$ is called an extended Branciari $b$-distance if it satisfies:

(i) $d_{e}(x, y)=0$ if and only if $x=y$;

(ii) $d_{e}(x, y)=d_{e}(y, x)$;

(iii) $d_{e}(x, y) \leq \omega(x, y)\left[d_{e}(x, u)+d_{e}(u, v)+d_{e}(v, y)\right]$

for all $x, y \in \mathcal{S}$ and all distinct $u, v \in \mathcal{S} \backslash\{x, y\}$. The couple of symbols $\left(S, d_{e}\right)$ denotes an extended Branciari $b$-distance space (shortly, $d_{e}$-metric space).

Example 1 Let $S=l_{p}$, where $1 \leq p<\infty$, be defined by

$$
l_{p}=\left\{\left(x_{n}\right)_{n \geq 1} \subseteq \mathbb{R}: \sum_{n=1}^{\infty}\left|x_{n}\right|^{p}<\infty\right\} .
$$

Define $d_{e}: S \times S \rightarrow \mathbb{R}^{+}$by

$$
d_{e}(x, y)=\left(\sum_{n=1}^{\infty}\left|x_{n}-y_{n}\right|^{p}\right)^{\frac{1}{p}} \quad \text { for all } x, y \in S
$$

The function $\omega: S \times S \rightarrow[1, \infty)$ is defined by $\omega(x, y)=2^{\frac{1}{p}}$ for all $x, y \in S$. Then $d_{e}$ satisfies all the conditions of an extended Branciari $b$-distance space. Indeed if $p=1$, the quadrilateral 
inequality trivially holds. So, let $p>1$ and $x=\left(x_{n}\right)_{n \geq 1} ; y=\left(y_{n}\right)_{n \geq 1} ; z=\left(z_{n}\right)_{n \geq 1} ; w=\left(w_{n}\right)_{n \geq 1}$ be sequences in $S$ with $y, w \in S \backslash\{x, z\}$. Consider

$$
\begin{aligned}
\left|x_{n}-z_{n}\right|^{p} \leq & p\left|x_{n}-z_{n}\right|^{p} \\
= & p\left|x_{n}-z_{n}\right|\left|x_{n}-z_{n}\right|^{p-1} \\
= & p\left[\left|x_{n}-y_{n}+y_{n}-w_{n}+w_{n}-z_{n}\right|\right]\left|x_{n}-z_{n}\right|^{p-1} \\
\leq & p\left[\left|x_{n}-y_{n}\right|+\left|y_{n}-w_{n}\right|+\left|w_{n}-z_{n}\right|\right]\left|x_{n}-z_{n}\right|^{p-1} \\
= & p\left[\left|x_{n}-y_{n}\right|\left|x_{n}-z_{n}\right|^{p-1}+\left|y_{n}-w_{n}\right|\left|x_{n}-z_{n}\right|^{p-1}\right. \\
& \left.+\left|w_{n}-z_{n}\right|\left|x_{n}-z_{n}\right|^{p-1}\right] \text { for } n \in \mathbb{N}, \\
\sum_{n=1}^{\infty}\left|x_{n}-z_{n}\right|^{p} \leq & p\left\{\sum_{n=1}^{\infty}\left|x_{n}-y_{n}\right|\left|x_{n}-z_{n}\right|^{p-1}\right. \\
& +\sum_{n=1}^{\infty}\left|y_{n}-w_{n}\right|\left|x_{n}-z_{n}\right|^{p-1} \\
& \left.+\sum_{n=1}^{\infty}\left|w_{n}-z_{n}\right|\left|x_{n}-z_{n}\right|^{p-1}\right\} \\
\leq & p\left\{\left(\sum_{n=1}^{\infty}\left|x_{n}-y_{n}\right|^{p}\right)^{\frac{1}{p}}\right. \\
& +\left(\sum_{n=1}^{\infty}\left|y_{n}-w_{n}\right|^{p}\right)^{\frac{1}{p}} \\
& \left.+\left(\sum_{n=1}^{\infty}\left|w_{n}-z_{n}\right|^{p}\right)^{\frac{1}{p}}\right\}\left(\sum_{n=1}^{\infty}\left|x_{n}-z_{n}\right|^{p(p-1)}\right)^{\frac{1}{p}} .
\end{aligned}
$$

After simplifying we get

$$
\begin{aligned}
\left(\sum_{n=1}^{\infty}\left|x_{n}-z_{n}\right|^{p}\right)^{\frac{1}{p}} \leq & p\left\{\left(\sum_{n=1}^{\infty}\left|x_{n}-y_{n}\right|^{p}\right)^{\frac{1}{p}}+\left(\sum_{n=1}^{\infty}\left|y_{n}-w_{n}\right|^{p}\right)^{\frac{1}{p}}\right. \\
& \left.+\left(\sum_{n=1}^{\infty}\left|w_{n}-z_{n}\right|^{p}\right)^{\frac{1}{p}}\right\} \\
\leq & 2^{p}\left\{\left(\sum_{n=1}^{\infty}\left|x_{n}-y_{n}\right|^{p}\right)^{\frac{1}{p}}+\left(\sum_{n=1}^{\infty}\left|y_{n}-w_{n}\right|^{p}\right)^{\frac{1}{p}}\right. \\
& \left.+\left(\sum_{n=1}^{\infty}\left|w_{n}-z_{n}\right|^{p}\right)^{\frac{1}{p}}\right\} \text { for } 1 \leq p<\infty .
\end{aligned}
$$

Thus $d_{e}(x, z) \leq \omega(x, z)\left[d_{e}(x, y)+d_{e}(y, w)+d_{e}(w, z)\right]$ and $d_{e}$ is an extended Branciari $b$ distance space. 
Example 2 Let $S=[0,1]$. Define $d_{e}: S \times S \rightarrow \mathbb{R}$ by $\omega(x, y)=5 x+5 y+3$, then $\left(S, d_{e}\right)$ is an extended Branciari $b$-distance space.

We will prove the extended quadrilateral inequality only as the other conditions are clear.

$$
\begin{aligned}
d_{e}(x, y)= & |x-y|^{2} \\
= & |x-z+z-w+w-y|^{2} \\
= & |x-z|^{2}+|z-w|^{2}+|w-y|^{2}+2|x-z||z-w| \\
& +2|z-w||w-y|+2|w-y||x-z| \\
\leq & (5 x+5 y+3)\left[|x-z|^{2}+|z-w|^{2}+|w-y|^{2}\right] \\
= & \omega(x, y)\left[d_{e}(x, z)+d_{e}(z, w)+d_{e}(w, y)\right] .
\end{aligned}
$$

Hence $d_{e}(x, y) \leq \omega(x, y)\left[d_{e}(x, z)+d_{e}(z, w)+d_{e}(w, y)\right]$.

Remark 1 If $\theta(x, y)=s$ for $s \geq 1$, then we obtain the definition of Branciari $b$-distance and $s=1$ yields the standard Branciari distance. As is known well, $b$-metric does not need to be continuous. Consequently, an extended Branciari $b$-distance is not necessarily continuous either. In this paper, we presume that each extended Branciari $b$-distance is continuous.

Definition 4 Let $S$ be a non-empty set endowed with extended Branciari $b$-distance $d_{e}$.

(a) A sequence $\left\{x_{n}\right\}$ in $S$ converges to $x$ if for every $\epsilon>0$ there exists $N=N(\epsilon) \in \mathbb{N}$ such that $d_{e}\left(x_{n}, x\right)<\epsilon$ for all $n \geq N$. For this particular case, we write $\lim _{n \rightarrow \infty} x_{n}=x$.

(b) A sequence $\left\{x_{n}\right\}$ in $S$ is called Cauchy if for every $\epsilon>0$ there exists $N=N(\epsilon) \in \mathbb{N}$ such that $d_{e}\left(x_{m}, x_{n}\right)<\epsilon$ for all $m, n \geq N$.

(c) A $d_{e}$-metric space $\left(S, d_{e}\right)$ is complete if every Cauchy sequence in $S$ is convergent.

Motivated and inspired by the above concerns, we have organized the article as follows:

- In Sect. 1 , the concept of an extended Branciari $b$-distance space is introduced and needed definitions are presented.

- In Sect. 2, various topics called $\Theta$-Branciari contraction, Ćirić-Reich-Rus type $\Theta$-Branciari contraction, and interpolative- $\Theta$-Branciari contraction are introduced. By using these new contractions, we formulate and prove some fixed point theorems in the setting of extended Branciari $b$-distance spaces.

- A supporting example is presented by using various sequences.

- In Sect. 3, as an application, we present a solution for a fourth-order differential equation boundary value problem.

\section{Main results}

Now, we start this section by introducing the concept of $\Theta$-Branciari contraction.

Definition 5 Let $\left(S, d_{e}\right)$ be an extended Branciari $b$-distance space and $T: X \rightarrow X$ be a mapping. Then $T$ is said to be a $\Theta$-Branciari contraction if there exists a function $\theta \in \Theta$ such that

$$
\theta\left(d_{e}(T x, T y)\right) \leq\left[\theta\left(d_{e}(x, y)\right)\right]^{r} \quad \text { if } d_{e}(T x, T y) \neq 0 \text { for } x, y \in S,
$$

where $r \in(0,1)$ is such that $\sup _{m \geq 1} \lim _{n \rightarrow \infty} \omega\left(x_{n}, x_{m}\right)<\frac{1}{r}$, where $x_{n}=T^{n} x_{0}$ for $x_{0} \in S$. 
Theorem 1 Let $\left(S, d_{e}\right)$ be a complete extended Branciari b-distance and $T: X \rightarrow X$ be a $\Theta$-Branciari contraction. Then $T$ has a unique fixed point in $S$.

Proof For an arbitrary point $x_{0} \in S$, we construct an iterative sequence $\left\{x_{n}\right\}_{0}$ as follows:

$$
x_{n}=T^{n} x_{0} \quad \text { for all } n \in \mathbb{N} \text {. }
$$

Suppose that if $T^{n_{*}} x=T^{n_{*}+1} x$ for some $n_{*} \in \mathbb{N}$, then $T^{n_{*}} x$ is clearly a fixed point of $T$.

Hence, without loss of generality, we may assume that $d_{e}\left(T^{n} x, T^{n+1} x\right)>0$ for all $n \in \mathbb{N}$. From Definition 5, we have

$$
\begin{aligned}
\theta\left(d_{e}\left(x_{n}, x_{n+1}\right)\right) & =\theta\left(d_{e}\left(T x_{n-1}, T x_{n}\right)\right) \\
& \leq\left[\theta\left(d_{e}\left(x_{n-1}, x_{n}\right)\right)\right]^{r} \\
& \leq\left[\theta\left(d_{e}\left(x_{n-2}, x_{n-1}\right)\right)\right]^{r^{2}} .
\end{aligned}
$$

Recursively, we find that

$$
\theta\left(d_{e}\left(x_{n}, x_{n+1}\right)\right) \leq\left[\theta\left(d_{e}\left(x_{0}, x_{1}\right)\right)\right]^{r^{n}} .
$$

Accordingly, we obtain that

$$
1<\theta\left(d_{e}\left(x_{n}, x_{n+1}\right)\right) \leq\left[\theta\left(d_{e}\left(x_{0}, x_{1}\right)\right)\right]^{r^{n}} \text { for all } n \in \mathbb{N} \text {. }
$$

Letting $n \rightarrow \infty$ in (2.3), we get $\theta\left(d_{e}\left(x_{n}, x_{n+1}\right)\right) \rightarrow 1$ as $n \rightarrow \infty$.

From $(\dagger)$, we have

$$
\lim _{n \rightarrow \infty} d_{e}\left(x_{n}, x_{n+1}\right)=0
$$

Similarly, we can easily deduce that

$$
\lim _{n \rightarrow \infty} d_{e}\left(x_{n}, x_{n+2}\right)=0
$$

From $(\ddagger)$, there exist $q \in(0,1)$ and $l \in(0, \infty]$ such that

$$
\lim _{n \rightarrow \infty} \frac{\theta\left(d_{e}\left(x_{n}, x_{n+1}\right)\right)-1}{\left[d_{e}\left(x_{n}, x_{n+1}\right)\right]^{q}}=l
$$

Suppose that $l<\infty$. In this case, let $B=\frac{l}{2}>0$. Using limit definition, we pick $n_{0} \in \mathbb{N}$ such that

$$
\left|\frac{\theta\left(d_{e}\left(x_{n}, x_{n+1}\right)\right)-1}{\left[d_{e}\left(x_{n}, x_{n+1}\right)\right]^{q}}-l\right| \leq B
$$

for all $n \geq n_{0}$.

This implies that $\left|\frac{\theta\left(d_{e}\left(x_{n}, x_{n+1}\right)\right)-1}{\left[d_{e}\left(x_{n}, x_{n+1}\right)\right]^{q}}\right| \geq l-B=B$ for all $n \geq n_{0}$. 
Then, we derive that

$$
n\left[d_{e}\left(x_{n}, x_{n+1}\right)^{q}\right] \leq n\left[\frac{\theta\left(d_{e}\left(x_{n}, x_{n+1}\right)\right)-1}{B}\right] \text { for all } n \geq n_{0}
$$

Suppose that $l=\infty$. Let $B>0$ be an arbitrary positive number.

Using the limit definition, we find $n_{0} \in \mathbb{N}$ such that $\frac{\theta\left(d_{e}\left(x_{n}, x_{n+1}\right)\right)-1}{\left[d_{e}\left(x_{n}, x_{n+1}\right)\right]^{q}} \geq B$ for all $n \geq n_{0}$.

This implies that

$$
n\left[d_{e}\left(x_{n}, x_{n+1}\right)\right]^{q} \leq n\left[\frac{\theta\left(d_{e}\left(x_{n}, x_{n+1}\right)\right)-1}{B}\right] \text { for all } n \geq n_{0}
$$

Thus, in all cases, there exist $\frac{1}{B}>0$ and $n_{0} \in \mathbb{N}$ such that

$$
n\left[d_{e}\left(x_{n}, x_{n+1}\right)\right]^{q} \leq n\left[\frac{\theta\left(d_{e}\left(x_{n}, x_{n+1}\right)\right)-1}{B}\right] \text { for all } n \geq n_{0}
$$

Using Eq. (2.3), we obtain

$$
n\left[d_{e}\left(x_{n}, x_{n+1}\right)\right]^{q} \leq\left[\theta\left(d_{e}\left(x_{0}, x_{1}\right)\right)\right]^{r^{n}}-1 \quad \text { for all } n \geq n_{0} .
$$

If we let $n \rightarrow \infty$ in the above inequality, then we obtain

$$
\lim _{n \rightarrow \infty} n\left[d_{e}\left(x_{n}, x_{n+1}\right)\right]^{q}=0 .
$$

Thus, there exists $n_{1} \in \mathbb{N}$ such that

$$
d_{e}\left(x_{n}, x_{n+1}\right) \leq \frac{1}{n^{\frac{1}{q}}} \quad \text { for all } n \geq n_{1}
$$

Let $N=\max \left\{n_{0}, n_{1}\right\}$. Due to the modified triangle inequality, we have two cases.

For all $n \geq 1$, we have two cases as follows.

Case 1: Let $x_{n}=x_{m}$ for some integers $n \neq m$. So, for $m>n$, we have $T^{m-n}\left(x_{n}\right)=x_{n}$. Choose $y=x_{n}$ and $p=m-n$. Then $T^{p} y=y$, that is, $y$ is a periodic point of $T$. Thus, $d_{e}(y, T y)=$ $d_{e}\left(T^{p} y, T^{p+1} y\right)$. Thus, by the above argument, we can easily deduce that $d_{e}(y, T y)=0$, so $y=T y$, that is, $y$ is a fixed point of $T$.

Case 2: Suppose that $T^{n} x \neq T^{m} x$ for all integers $n \neq m$. Let $n<m$ be two natural numbers. To show that $\left\{x_{n}\right\}$ is a Cauchy sequence, we need to consider two subcases as follows.

Subcase 1: We claim that if $n-m$ is odd, then $d_{e}\left(x_{n}, x_{m}\right)$ converges to 0 as $n, m \rightarrow \infty$ To prove this, we may assume that $m=n+2 p+1$. Thus,

$$
\begin{aligned}
d_{e}\left(x_{n}, x_{n+2 p+1}\right) \leq & w\left(x_{n}, x_{n+2 p+1}\right)\left[d_{e}\left(x_{n}, x_{n+1}\right)+d_{e}\left(x_{n+1}, x_{n+2}\right)+d_{e}\left(x_{n+2}, x_{n+2 p+1}\right)\right] \\
\leq & w\left(x_{n}, x_{n+2 p+1}\right) d_{e}\left(x_{n}, x_{n+1}\right)+w\left(x_{n}, x_{n+2 p+1}\right) d_{e}\left(x_{n+1}, x_{n+2}\right) \\
& +w\left(x_{n}, x_{n+2 p+1}\right) w\left(x_{n+2}, x_{n+2 p+1}\right)\left[d_{e}\left(x_{n+2}, x_{n+3}\right)\right. \\
& \left.+d_{e}\left(x_{n+3}, x_{n+4}\right)+d_{e}\left(x_{n+4}, x_{n+2 p+1}\right)\right] \\
\leq & w\left(x_{n}, x_{n+2 p+1}\right) d_{e}\left(x_{n}, x_{n+1}\right)+w\left(x_{n}, x_{n+2 p+1}\right) d_{e}\left(x_{n+1}, x_{n+2}\right)
\end{aligned}
$$




$$
\begin{aligned}
& \quad+w\left(x_{n}, x_{n+2 p+1}\right) w\left(x_{n+2}, x_{n+2 p+1}\right) d_{e}\left(x_{n+2}, x_{n+3}\right) \\
& \quad+w\left(x_{n}, x_{n+2 p+1}\right) w\left(x_{n+2}, x_{n+2 p+1}\right) d_{e}\left(x_{n+3}, x_{n+4}\right) \\
& \quad+w\left(x_{n}, x_{n+2 p+1}\right) w\left(x_{n+2}, x_{n+2 p+1}\right) d_{e}\left(x_{n+4}, x_{n+2 p+1}\right) \\
& \leq \ldots \\
& \leq w\left(x_{n}, x_{n+2 p+1}\right) d_{e}\left(x_{n}, x_{n+1}\right)+w\left(x_{n}, x_{n+2 p+1}\right) d_{e}\left(x_{n+1}, x_{n+2}\right) \\
& +w\left(x_{n}, x_{n+2 p+1}\right) w\left(x_{n+2}, x_{n+2 p+1}\right) d_{e}\left(x_{n+2}, x_{n+3}\right) \\
& +w\left(x_{n}, x_{n+2 p+1}\right) w\left(x_{n+2}, x_{n+2 p+1}\right) d_{e}\left(x_{n+3}, x_{n+4}\right)+\cdots \\
& \quad+w\left(x_{n}, x_{n+2 p+1}\right) w\left(x_{n+2}, x_{n+2 p+1}\right) \cdots \\
& \quad \times w\left(x_{n+2 p-2}, x_{n+2 p+1}\right) d_{e}\left(x_{n+2 p}, x_{n+2 p+1}\right) .
\end{aligned}
$$

This can be written as follows:

$$
d_{e}\left(x_{n}, x_{m}\right) \leq \sum_{j=n}^{n+m-1} d_{e}\left(x_{j}, x_{j+1}\right) \prod_{i=n}^{n+m-1} \omega\left(x_{i}, x_{m}\right)
$$

Since $\sup _{m \geq 1} \lim _{n \rightarrow \infty} \omega\left(x_{n}, x_{m}\right)<\frac{1}{r}$, we have

$$
d_{e}\left(x_{n}, x_{m}\right) \leq \sum_{j=n}^{n+m-1} d_{e}\left(x_{j}, x_{j+1}\right) \prod_{i=n}^{n+m-1} \omega\left(x_{i}, x_{m}\right) \leq \frac{1}{r} \sum_{j=n}^{\infty} \frac{1}{j^{\frac{1}{q}}}
$$

which is convergent to 0 as $n, m \rightarrow \infty$ and $\frac{1}{q}>1$.

Subcase 2: We claim that if $n-m$ is even, then $d_{e}\left(x_{n}, x_{m}\right)$ converges to 0 as $n, m \rightarrow \infty$. To prove this, we may assume that $m=n+2 p$. Thus,

$$
d_{e}\left(x_{n}, x_{n+2 p}\right) \leq w\left(x_{n}, x_{n+2 p}\right)\left[d_{e}\left(x_{n}, x_{n-2}\right)+d_{e}\left(x_{n-2}, x_{n+2 p+1}\right)+d_{e}\left(x_{n+2 p}, x_{n+2 p+1}\right)\right]
$$

Hence, by the fact that $\sup _{m \geq 1} \lim _{n \rightarrow \infty} \omega\left(x_{n}, x_{m}\right)<\frac{1}{r}$, subcase $1,(2.4)$, and (2.5), we can easily deduce that $d_{e}\left(x_{n}, x_{m}\right)$ converges to 0 as $n, m \rightarrow \infty$. Thus, the sequence $\left\{x_{n}\right\}$ in $S$ is a Cauchy sequence.

Since $\left(S, d_{e}\right)$ is a complete extended Branciari $b$-distance, there exists a point $\eta$ in $S$ such that $\left\{x_{n}\right\}$ converges to $\eta$.

Next, we indicate that $T$ is continuous. Suppose that if $T x \neq T y$, then from (2.2) we have

$$
\begin{aligned}
\ln \left[\theta d_{e}(T x, T y)\right] & \leq r \ln \left[\theta d_{e}(x, y)\right] \\
& \leq \ln \left[\theta d_{e}(x, y)\right] .
\end{aligned}
$$

Since $\theta$ is non-decreasing, we derive, from the above observation, that $d_{e}(T x, T y) \leq d_{e}(x, y)$ for all distinct $x, y \in S$.

From this inspection, we can get $d_{e}\left(x_{n+1}, T \eta\right)=d_{e}\left(T x_{n}, T \eta\right) \leq d_{e}\left(x_{n}, \eta\right)$ for all $n \in \mathbb{N}$.

Letting $n \rightarrow \infty$ in the above inequality, we get $x_{n+1} \rightarrow T \eta$.

From the rectangle inequality, we have

$$
d_{e}(\eta, T \eta) \leq \omega(\eta, T \eta)\left[d_{e}\left(\eta, x_{n}\right)+d_{e}\left(x_{n}, x_{n+1}\right)+d_{e}\left(x_{n+1}, T \eta\right)\right] .
$$


Taking limit as $n \rightarrow \infty$ and using (2.6) and Definition 3 of (i), we have $d_{e}(\eta, T \eta)=0$, which implies that $T \eta=\eta$.

This contradicts the assumption that $T$ does not have a periodic point. Hence, assume that $\eta$ is a periodic point of $T$ with period $q$.

Suppose that the set of fixed points of $T$ is empty.

Then we have $d_{e}(z, T z)>0$ for all $z \in S$ and $d_{e}\left(z, T^{q} z\right)=0$ for $q>1$.

Using Definition 5, we get

$$
\begin{aligned}
\theta\left(d_{e}(z, T z)\right) & =\theta\left(d_{e}\left(T^{q} z, T^{q+1} z\right)\right) \leq\left[\theta\left(d_{e}(z, T z)\right)\right]^{r^{q}} \\
& <\theta\left(d_{e}(z, T z)\right)
\end{aligned}
$$

which leads to a contradiction. So, there exists a point $\eta \in S$ such that $T \eta=\eta$.

Suppose that $f$ has another fixed point $\zeta$ such that $\eta \neq \zeta$. Then clearly $d_{e}(\eta, \zeta)=$ $d_{e}(f \eta, f \zeta) \neq 0$.

Now, using condition (2.1), we get

$$
\begin{aligned}
\theta\left(d_{e}(\eta, \zeta)\right) & =\theta\left(d_{e}(T \eta, T \zeta)\right) \\
& =\theta\left(d_{e}\left(T^{q} \eta, T^{q} \zeta\right)\right) \leq\left[\theta\left(d_{e}(\eta, \zeta)\right)\right]^{r^{q}} \\
& <\theta\left(d_{e}(\eta, \zeta)\right), \quad \text { a contradiction. }
\end{aligned}
$$

Therefore, $\eta=\zeta$. This claims that $T$ has a unique fixed point in $S$.

Example 3 Consider the sequence:

$$
\begin{aligned}
& \tau_{1}=1 \times 2, \\
& \tau_{2}=1 \times 2+2 \times 3, \\
& \tau_{3}=1 \times 2+2 \times 3+3 \times 4, \\
& \tau_{4}=1 \times 2+2 \times 3+3 \times 4+4 \times 5, \\
& \tau_{n}=1 \times 2+2 \times 3+3 \times 4+4 \times 5+\cdots+n(n+1)=\frac{n(n+1)(n+2)}{3} .
\end{aligned}
$$

Let $S=\left\{\tau_{n}: n \in \mathbb{N}\right\}$. Define $d_{e}: S \times S \rightarrow[0, \infty)$ as $d_{e}(x, y)=|x-y|^{2}$ and $\omega: S \times S \rightarrow[1, \infty)$ as $\omega(x, y)=4 x+2 y+3$. Then $\left(S, d_{e}\right)$ is a complete extended $b$-Branciari distance space.

Define the mapping $T: S \rightarrow S$ by $T\left(\tau_{1}\right)=\tau_{1}, T\left(\tau_{n}\right)=\tau_{n-1}$ for all $n \geq 2$. Now we show that $T$ is a $\Theta$-Branciari contraction with $\theta(t)=e^{t}$.

Since $\theta\left(d_{e}(T x, T y)\right) \leq\left[\theta\left(d_{e}(x, y)\right)\right]^{r}$, which yields $e^{\left(d_{e}(T x, T y)\right)} \leq\left[e^{\left(d_{e}(x, y)\right)}\right]^{r}$. Applying log on both sides, we get

$$
d_{e}(T x, T y) \leq r d_{e}(x, y)
$$

Thus to prove $T$ is a $\Theta$-Branciari contraction, it suffices to prove the above equation. 
Case-1: For $n=1$ and $m>2$, we have

$$
\begin{aligned}
d_{e}\left(T \tau_{1}, T \tau_{m}\right) & =d_{e}\left(\tau_{1}, \tau_{m-1}\right) \\
& =\left|\frac{m(m-1)(m+1)-6}{3}\right|^{2}
\end{aligned}
$$

and

$$
d_{e}\left(\tau_{1}, \tau_{m}\right)=\left|\frac{m(m+1)(m+2)-6}{3}\right|^{2} .
$$

Now consider

$$
\begin{aligned}
\frac{d_{e}\left(T \tau_{1}, T \tau_{m}\right)}{d_{e}\left(\tau_{1}, \tau_{m}\right)} & =\left|\frac{m(m-1)(m+1)-6}{m(m+1)(m+2)-6}\right|^{2} \\
& <r, \quad \text { where } r \in(0,1) .
\end{aligned}
$$

Case-2: For $m>n>1$, we have

$$
\begin{aligned}
d_{e}\left(T \tau_{n}, T \tau_{m}\right) & =d_{e}\left(\tau_{n-1}, \tau_{m-1}\right) \\
& =d_{e}\left(\frac{(n-1) n(n+1)}{3}, \frac{(m-1) m(m+1)}{3}\right) \\
& =\left|\frac{(n-1) n(n+1)}{3}-\frac{(m-1) m(m+1)}{3}\right|^{2} \\
& =\left|\frac{n^{3}-n}{3}-\frac{m^{3}-m}{3}\right|^{2} \\
& =\left|\frac{n^{3}-m^{3}-(n-m)}{3}\right|^{2} \\
& =\left|\frac{(n-m)\left(n^{2}+n m+m^{2}\right)-(n-m)}{3}\right|^{2} \\
& =\left|\frac{(n-m)\left(n^{2}+n m+m^{2}-1\right)}{3}\right|^{2}
\end{aligned}
$$

and

$$
\begin{aligned}
d_{e}\left(\tau_{n}, \tau_{m}\right) & =d_{e}\left(\frac{n(n+1)(n+2)}{3}, \frac{m(m+1)(m+2)}{3}\right) \\
& =\left|\frac{n(n+1)(n+2)}{3}-\frac{m(m+1)(m+2)}{3}\right|^{2} \\
& =\left|\frac{n^{3}+3 n^{2}+2 n}{3}-\frac{m^{3}+3 m^{2}+2 m}{3}\right|^{2} \\
& =\left|\frac{n^{3}-m^{3}-3\left(n^{2}-m^{2}\right)+2(n-m)}{3}\right|^{2} \\
& =\left|\frac{(n-m)\left(n^{2}+n m+m^{2}\right)+3(n+m)+2}{3}\right|^{2} .
\end{aligned}
$$


Now consider

$$
\begin{aligned}
\frac{d_{e}\left(T \tau_{n}, T \tau_{m}\right)}{d_{e}\left(\tau_{n}, \tau_{m}\right)} & =\left|\frac{n^{2}+n m+m^{2}-1}{n^{2}+n m+m^{2}+3(n+m)+2}\right|^{2} \\
& <r, \quad \text { where } r \in(0,1) .
\end{aligned}
$$

Thus $T$ satisfies $\Theta$-Branciari contraction with $\theta(t)=e^{t}$. Then, from Theorem 1, $T$ has a unique fixed point $\tau_{1}$.

If we take $\omega(x, y)=b>1$ in Theorem 1, then we get the following corollary.

Corollary 1 Let $T$ be a self-map on a complete Branciari b-distance space $(X, d)$. Suppose that there exist $\vartheta \in \Theta$ and $r \in(0,1)$ such that

$$
\vartheta(d(T x, T y)) \leq[\vartheta(d(x, y))]^{r} \quad \text { if } d(T x, T y) \neq 0 \text { for } x, y \in S .
$$

Then $T$ has a unique fixed point in $S$.

If we take $\omega(x, y)=1$ in the above theorem, then we get the following corollary.

Corollary 2 Let $T$ be a self-map on a complete Branciari distance space. If there exist $\vartheta \in \Theta$ and $r \in(0,1)$ such that

$$
\vartheta(d(T x, T y)) \leq[\vartheta(d(x, y))]^{r} \quad \text { if } d(T x, T y) \neq 0 \text { for } x, y \in S,
$$

then $T$ possesses a unique fixed point in $S$.

Definition 6 Let $\left(S, d_{e}\right)$ be a $d_{e}$-metric space. A mapping $f: S \rightarrow S$ is called Ćirić-ReichRus type $\Theta$-Branciari contraction, in short, CRR- $\Theta$-Branciari contraction, if there exist a function $\theta \in \Theta$ and a non-negative real number $r<1$ such that

$$
\theta\left(d_{e}(f x, f y)\right) \leq\left[M_{f, \theta}(x, y)\right]^{r}
$$

for all $x, y \in S$, where

$$
M_{f, \theta}(x, y):=\max \left\{\theta\left(d_{e}(x, y)\right), \theta\left(d_{e}(y, f y)\right)\right\}
$$

where $\lim \sup _{n, m \rightarrow \infty} \omega\left(x_{n}, x_{m}\right)<\frac{1}{r}$, here $x_{n}=f^{n} x_{0}$ for $x_{0} \in S$ and $r \in(0,1)$.

Theorem 2 Let $\left(S, d_{e}\right)$ be a complete extended Branciari b-distance space and $f: S \rightarrow S$ be a CRR- $\Theta$-Branciari contraction. Then $f$ has a unique fixed point in $S$.

Proof As in Theorem 1, we construct an iterative sequence $\left\{x_{n}\right\}_{0 \infty}$ by starting an arbitrary point $x_{0} \in S$ as follows:

$$
x_{n}=f^{n} x_{0} \quad \text { for all } n \in \mathbb{N} \text {. }
$$


Without loss of generality, we assume that $d_{e}\left(f^{n} x, f^{n+1} x\right)>0$ for all $n \in \mathbb{N}$. Indeed, if $f^{n_{*}} x=$ $f^{n_{*}+1} x$ for some $n_{*} \in \mathbb{N}$, then $f^{n_{*}} x$ will be a fixed point of $T$.

We prove thatlim ${ }_{n \rightarrow \infty} d_{e}\left(x_{n}, x_{n+1}\right)=0$.

Employing the contraction condition (2.8), we get

$$
\theta\left(d_{e}\left(x_{n+1}, x_{n}\right)\right) \leq\left[M_{f, \theta}\left(x_{n}, x_{n-1}\right)\right]^{r},
$$

where

$$
\begin{aligned}
M_{f, \theta}\left(x_{n}, x_{n-1}\right) & =\max \left\{\theta\left(d_{e}\left(x_{n}, x_{n-1}\right)\right), \theta\left(d_{e}\left(x_{n}, f x_{n}\right)\right), \theta\left(d_{e}\left(x_{n-1}, f x_{n-1}\right)\right)\right\} \\
& =\max \left\{\theta\left(d_{e}\left(x_{n}, x_{n-1}\right)\right), \theta\left(d_{e}\left(x_{n}, x_{n+1}\right)\right), \theta\left(d_{e}\left(x_{n-1}, x_{n}\right)\right)\right\} . \\
& \leq \max \left\{\theta\left(d_{e}\left(x_{n}, x_{n-1}\right)\right), \theta\left(d_{e}\left(x_{n}, x_{n+1}\right)\right)\right\} .
\end{aligned}
$$

If $M_{f, \theta}\left(x_{n}, x_{n-1}\right)=\theta\left(d_{e}\left(x_{n}, x_{n+1}\right)\right)$, then inequality (2.9) becomes

$$
\theta\left(d_{e}\left(x_{n+1}, x_{n}\right)\right) \leq \theta\left(d_{e}\left(x_{n}, x_{n+1}\right)\right)^{r} \Leftrightarrow \ln \left(\theta\left(d_{e}\left(x_{n+1}, x_{n}\right)\right)\right) \leq r \ln \left(\theta\left(d_{e}\left(x_{n+1}, x_{n}\right)\right)\right),
$$

which is a contradiction (since $r<1)$. Thus, we have $M_{f, \theta}\left(x_{n}, x_{n-1}\right)=\theta\left(d_{e}\left(x_{n-1}, x_{n}\right)\right)$. It yields from (2.9) that

$$
\theta\left(d_{e}\left(x_{n}, x_{n+1}\right)\right) \leq\left[\theta\left(d_{e}\left(x_{n-1}, x_{n}\right)\right)\right]^{r}
$$

Iteratively, we find that

$$
\theta\left(d_{e}\left(x_{n}, x_{n+1}\right)\right) \leq\left[\theta\left(d_{e}\left(x_{0}, x_{1}\right)\right)\right]^{r^{n}} .
$$

After this observation, by following the related lines in the proof of Theorem 2, we conclude that the sequence $\left\{x_{n}\right\}$ in $S$ is a Cauchy sequence. Regarding that $\left(S, d_{e}\right)$ is a complete extended Branciari $b$-distance, there exists a point $\eta$ in $S$ such that $\left\{x_{n}\right\}$ converges to $\eta$.

Without loss of generality, we assume that $f^{n} x \neq \eta$ for all $n$ (or for large enough $n$ ). Assume that $d(\eta, T \eta)>0$. Employing (2.8), we get

$$
\theta\left(d_{e}\left(f x_{n}, f \eta\right)\right) \leq\left[M_{f, \theta}\left(x_{n}, \eta\right)\right]^{r}
$$

for all $x, y \in S$, where

$$
M_{f, \theta}\left(x_{n}, \eta\right):=\max \left\{\theta\left(d_{e}\left(x_{n}, \eta\right)\right), \theta\left(d_{e}\left(x_{n}, f x_{n}\right)\right), \theta\left(d_{e}(\eta, f \eta)\right)\right\}
$$

By taking $n \rightarrow \infty$ in the inequality above, we derive that

$$
\theta\left(d_{e}(\eta, f \eta)\right) \leq\left[\theta\left(d_{e}(\eta, f \eta)\right)\right]^{r}<\theta\left(d_{e}(\eta, f \eta)\right)
$$

a contradiction. Hence, $f \eta=\eta$.

That is, $f$ has a fixed point in $S$.

Suppose that $\eta \neq \zeta$ are two fixed points of $f$. Then clearly $d_{e}(\eta, \zeta)=d_{e}(f \eta, f \zeta) \neq 0$. 
Now, using condition (2.11), we get

$$
\begin{aligned}
1 & <\theta\left(d_{e}(\eta, \zeta)\right)=\theta\left(d_{e}(f \eta, f \zeta)\right) \\
& \leq\left[\max \left\{\theta\left(d_{e}(\eta, \zeta)\right), \theta\left(d_{e}(\eta, f \eta)\right), \theta\left(d_{e}(\zeta, f \zeta)\right)\right\}\right]^{r} \\
& <\theta\left(d_{e}(\eta, \zeta)\right),
\end{aligned}
$$

a contradiction. Accordingly, we have $\eta=\zeta$.

Thus $f$ has a unique fixed point in $S$.

Definition 7 Let $\left(S, d_{e}\right)$ be an extended Branciari $b$-distance and $f: S \rightarrow S$ be a mapping. Then $f$ is said to be an interpolative- $\Theta$-Branciari contraction if there exist a function $\theta \in \Theta$ and non-negative real numbers $r_{1}, r_{2}, r_{3}$ with $r_{1}+r_{2}+r_{3}<1$ such that

$$
\theta\left(d_{e}(f x, f y)\right) \leq\left[\theta\left(d_{e}(x, y)\right)\right]^{r_{1}}\left[\theta\left(d_{e}(x, f x)\right)\right]^{r_{2}}\left[\theta\left(d_{e}(y, f y)\right)\right]^{r_{3}}
$$

for all $x, y \in S$, where $\lim \sup _{n, m \rightarrow \infty} \omega\left(x_{n}, x_{m}\right)<\frac{1}{r}$, here $x_{n}=f^{n} x_{0}$ for $x_{0} \in S$ and $r \in(0,1)$.

Theorem 3 Let $\left(S, d_{e}\right)$ be a complete extended Branciari b-distance where $d_{e}$ is a continuous functional. Iff $: S \rightarrow S$ is an interpolative- $\Theta$-Branciari contraction, then $f$ possesses a unique fixed point in $S$.

We skip the proof since

$$
\begin{aligned}
& {\left[\theta\left(d_{e}(x, y)\right)\right]^{r_{1}}\left[\theta\left(d_{e}(x, f x)\right)\right]^{r_{2}}\left[\theta\left(d_{e}(y, f y)\right)\right]^{r_{3}}} \\
& \quad \leq\left[M_{\theta, f}(x, y)\right]^{r_{1}+r_{2}+r_{3}} .
\end{aligned}
$$

Thus, it is sufficient to choose $r:=r_{1}+r_{2}+r_{3}<1$ in Theorem 2 to conclude the theorem above.

In Theorem 3, if we take $r_{2}=0, r_{3}=0$, then the above theorem reduces to the following.

Theorem 4 Let $f$ be a self-mapping on an extended Branciari b-distance space $\left(S, d_{e}\right)$ and $\theta \in \Theta$. If there exists $r_{1} \in[0,1)$ such that

$$
\theta\left(d_{e}(f x, f y)\right) \leq\left[\theta\left(d_{e}(x, y)\right)\right]^{r_{1}} \text { for all } x, y \in S
$$

where $r \in[0,1)$ and $\limsup _{m, n \rightarrow \infty} \omega\left(x_{n}, x_{m}\right)<\frac{1}{r}$, then $f$ has a unique fixed point in $S$.

In Theorem 3, if we take $r_{1}=0, r_{2}=0, r_{3}=0$, then the above theorem reduces to the following one.

Theorem 5 Let $\left(S, d_{e}\right)$ be an extended Branciari b-distance space such that $d_{e}$ is a continuous functional and $\theta \in \Theta, f: S \rightarrow S$ be a mapping. Suppose that there exists $r_{4} \in[0,1)$ such that

$$
\theta\left(d_{e}(f x, f y)\right) \leq\left[\theta\left(d_{e}(x, f y)+d_{e}(y, f x)\right)\right]^{r_{4}} \quad \text { for all } x, y \in S
$$

and $r \in[0,1)$ such that $\lim \sup _{m, n \rightarrow \infty} \omega\left(x_{n}, x_{m}\right)<\frac{1}{r}$. Consequently, $f$ possesses a unique fixed point in $S$. 


\section{Existence of a solution of fourth-order differential equation}

We consider the problem

$$
\left\{\begin{array}{l}
\xi^{4}(t)=g\left(t, \xi(t), \xi^{\prime}, \xi^{\prime \prime}, \xi^{\prime \prime \prime}\right), \\
\xi(0)=\xi^{\prime}(0)=\xi^{\prime \prime}(1)=\xi^{\prime \prime \prime}(1)=0 ; \quad t \in[0,1]
\end{array}\right.
$$

where $g:[0,1] \times \mathbb{R}^{3} \times \mathbb{R} \rightarrow \mathbb{R}$ is a continuous function. This problem known as a boundary value problem (shortly, BVP) is employed to model such phenomena as deformations of an elastic beam in its equilibrium state, where one end-point is free while the other is fixed. In the discipline of mechanics, boundary value problem is said to be a Cantilever beam equation. Due to its significance in mathematics, the existence of solutions for such a problem plays a vital role. With this inspiration, we shall employ the fixed point technique to find the existence of solution of BVP.

In this section, we study the existence of solution of a fourth-order differential equation boundary value problem. Let $S=\mathcal{C}[0,1]$, where $\mathcal{C}[0,1]$ represents the space of all continuous functions defined on the closed interval $[0,1]$. An extended Branciari $b$-distance space on $S$ is given by $d_{e}(\xi, y)=|\xi-y|^{2}$, where $d_{e}: S \times S \rightarrow \mathbb{R}$ and $\omega: S \times S \rightarrow[1, \infty)$ by $\omega(\xi, y)=5 \xi+5 y+3$.

Note that the space $S=\left(\mathcal{C}[0,1], d_{e}\right)$ is a complete extended Branciari $b$-distance space. Now, we consider the above fourth-order ordinary differential equation boundary value problem. Then the problem BVP can be written in the following integral form:

$$
\xi(t)=\int_{0}^{1} \mathcal{G}(t, s) g\left(s, \xi(s), \xi^{\prime}(s)\right) d s, \quad \xi \in \mathcal{C}[0,1]
$$

where $\mathcal{G}(t, s)$ is Green's function of the homogenous linear problem $\xi^{4}(t)=0, \xi(0)=\xi^{\prime}(0)=$ $\xi^{\prime \prime}(1)=\xi^{\prime \prime \prime}(1)=0$, which is explicitly given by

$$
\mathcal{G}(t, s)= \begin{cases}\frac{1}{6} t^{2}(3 s-t), & 0 \leq t \leq s \leq 1 \\ \frac{1}{6} s^{2}(3 t-s), & 0 \leq s \leq t \leq 1\end{cases}
$$

From (3.2), we can easily check that $\mathcal{G}(t, s)$ has the following properties: $\frac{1}{3} t^{2} s^{2} \leq \mathcal{G}(t, s) \leq$ $\frac{1}{2} t^{2}$ (or $\left.\frac{1}{2} s^{2}\right), t, s \in[0,1]$.

Theorem 6 Assume that the following conditions are satisfied:

(1) $g:[0,1] \times \mathbb{R}^{3} \times \mathbb{R} \rightarrow \mathbb{R}$ is continuous.

(2) There exists $\tau \in[1, \infty)$ such that the following condition holds for all $\xi, y \in S$ :

$$
\left|g\left(s, \xi, \xi^{\prime}\right)-g\left(s, y, y^{\prime}\right)\right| \leq \sqrt{20} e^{\frac{-\tau}{2}}|\xi(s)-y(s)|, \quad s \in[0,1] .
$$

(3) There exists $\xi_{0} \in X$ such that, for all $t \in[0,1]$, we have

$$
\xi_{0} t \leq \int_{0}^{1} \mathcal{G}(t, s) g\left(s, \xi_{0}(s), \xi_{0}^{\prime}(s)\right) d s
$$

Then the problem BVP has a solution in $S$. 
Proof If we define the mapping $f: S \rightarrow S$ by

$$
f(\xi)(t)=\int_{0}^{1} \mathcal{G}(t, s) g\left(s, \xi(s), \xi^{\prime}(s)\right) d s
$$

then $\xi=f \xi$, which yields that BVP has a unique solution. Consider

$$
\begin{aligned}
|f(\xi)(t)-f(y)(t)|^{2} & =\left|\int_{0}^{1} \mathcal{G}(t, s) g\left(s, \xi(s), \xi^{\prime}(s)\right) d s-\int_{0}^{1} \mathcal{G}(t, s) g\left(s, y(s), y^{\prime}(s)\right) d s\right|^{2} \\
& \leq \int_{0}^{1}(\mathcal{G}(t, s))^{2} \mid g\left(s, \xi(s), \xi^{\prime}(s)\right)-g\left(s, y(s),\left.y^{\prime}(s)\right|^{2} d s\right. \\
& \leq \int_{0}^{1} \frac{1}{4} s^{4} 20 e^{-\tau}|\xi(s)-y(s)|^{2} d s \\
& \leq 20 e^{-\tau} d_{e}(\xi, y) \int_{0}^{1} \frac{1}{4} s^{4} d s \\
& \leq 20 e^{-\tau} d_{e}(\xi, y) \frac{1}{20} \\
& =e^{-\tau} d_{e}(\xi, y)
\end{aligned}
$$

which yields

$$
\begin{aligned}
& d_{e}(f(\xi), f(y)) \leq e^{-\tau} d_{e}(\xi, y) \\
& \sqrt{d_{e}(f(\xi), f(y))} \leq \sqrt{e^{-\tau} d_{e}(\xi, y)} \\
& e^{\sqrt{d_{e}(f(\xi), f(y))}} \leq\left(e^{\sqrt{d_{e}(\xi, y)}}\right)^{\sqrt{e^{-\tau}}}, \quad \text { where } e^{-\tau}<1 \text { as } \tau \geq 1 .
\end{aligned}
$$

Hence $e^{\sqrt{d_{e}(f(\xi) f(y))}} \leq\left(e^{\sqrt{d_{e}(\xi, y)}}\right)^{r}$ with $r=\sqrt{e^{-\tau}}$, which gives

$$
\theta\left(d_{e}(f \xi, f y)\right) \leq\left[\theta\left(d_{e}(\xi, y)\right)\right]^{r}, \quad \text { where } \theta(t)=e^{\sqrt{t}} .
$$

As all the conditions of Theorem 4 are satisfied, $f$ has a fixed point. Thus BVP has a solution in $S$.

\section{Acknowledgements}

We would like to thank the anonymous reviewers for their constructive comments and helpful suggestions. The first author would like to thank Prince Sultan University for funding this work through research group Nonlinear Analysis Methods in Applied Mathematics (NAMAM), Group Number RG-DES-2017-01-17.

\section{Funding}

Not applicable.

Availability of data and materials

Not applicable.

\section{Competing interests}

The authors declare that they have no competing interests.

Authors' contributions

All authors contributed equally and significantly in writing this article. All authors read and approved the final manuscript. 


\section{Author details}

${ }^{1}$ Department of Mathematics and General Sciences, Prince Sultan University, Riyadh, Saudi Arabia. ${ }^{2}$ Department of Medical Research, China Medical University Hospital, China Medical University, Taichung, Taiwan. ${ }^{3}$ Department of Computer Science and Information Engineering, Asia University, Taichung, Taiwan. ${ }^{4}$ Department of Mathematics, Çankaya University, Ankara, Turkey. ${ }^{5}$ Department of Mathematics, GMR Institute of Technology, Rajam, India.

\section{Publisher's Note}

Springer Nature remains neutral with regard to jurisdictional claims in published maps and institutional affiliations.

\section{Received: 26 September 2019 Accepted: 7 April 2020 Published online: 16 April 2020}

\section{References}

1. Branciari, A.: A fixed point theorem for mappings satisfying a general contractive condition of integral type. Int. J. Math. Math. Sci. 29(9), 531-536 (2002)

2. Aydi, H., Karapınar, E., Samet B.: Fixed points for generalized $(\alpha, \psi)$-contractions on generalized metric spaces. J. Inequal. Appl. 2014, Article ID 229 (2014)

3. Aydi, H., Karapınar, E., Lakzian, H.: Fixed point results on the class of generalized metric spaces. Math. Sci. 6, Article ID $46(2012)$

4. Azam, A., Arshad, M.: Kannan fixed point theorems on generalized metric spaces. J. Nonlinear Sci. Appl. 1, 45-48 (2008)

5. Branciari, A.: A fixed point theorem of Banach-Caccioppoli type on a class of generalized metric spaces. Publ. Math. (Debr.) 57, 31-37 (2000)

6. Bilgili, N., Karapınar, E.: A note on "Common fixed points for $(\psi, \alpha, \beta)$-weakly contractive mappings in generalized metric spaces". Fixed Point Theory Appl. 2013, Article ID 287 (2013)

7. Das, P., Lahiri, B.K.: Fixed point of a Ljubomir Ćirić's quasi-contraction mapping in a generalized metric space. Publ. Math. (Debr.) 61, 589-594 (2002)

8. Kadeburg, Z., Radenović, S.: On generalized metric spaces: a survey. TWMS J. Pure Appl. Math. 5(1), 3-13 (2014)

9. Karapınar, E.: Discussion on $(\alpha, \psi)$ contractions on generalized metric spaces. Abstr. Appl. Anal. 2014, Article ID 962784 (2014)

10. Karapınar, E.: Fixed points results for $\alpha$-admissible mapping of integral type on generalized metric spaces. Abstr. Appl. Anal. 2014, Article ID 141409 (2014)

11. Karapınar, E.: On $(\alpha, \psi)$ contractions of integral type on generalized metric spaces. In: Mityushevand, V., Ruzhansky, M. (eds.) Proceedings of the 9th ISAAC Congress. Springer, Berlin (2013)

12. Panda, S.K., Abdeljawad, T., Ravichandran, C.: A complex valued approach to the solutions of Riemann-Liouville integral, Atangana-Baleanu integral operator and non-linear Telegraph equation via fixed point method. Chaos Solitons Fractals 130, Article ID 109439 (2020)

13. Mihet, D.: On Kannan fixed point principle in generalized metric spaces. J. Nonlinear Sci. Appl. 2, 92-96 (2009)

14. Suzuki, T.: Generalized metric space do not have the compatible topology. Abstr. Appl. Anal. 2014, Article ID 458098 (2014)

15. Abdeljawad, T., Mlaiki, N., Aydi, H., Souayah, N.: Double controlled metric type spaces and some fixed point results Mathematics 6(12), Article ID 320 (2018). https://doi.org/10.3390/math6120320

16. Abdeljawad, T., Abodayeh, K., Mlaiki, N.: On fixed point generalizations to partial b-metric spaces. J. Comput. Anal. Appl. 19(5), 883-891 (2015)

17. Mlaiki, N., Aydi, H., Souayah, N., Abdeljawad, T:: Controlled metric type spaces and the related contraction principle. Mathematics 6(10), Article ID 194 (2018). https://doi.org/10.3390/math6100194

18. Mukheimer, A.A.: $\alpha-\psi$-Contractive mappings on b-metric space. J. Comput. Anal. Appl. 18(4), 636-644 (2015)

19. Mlaiki, N., Zarrad, A., Souayah, N., Mukheimer, A., Abdeljawed, T.: Fixed point theorems in $M_{b}$-metric spaces. J. Math. Anal. 7(5), 1-9 (2016)

20. Karapınar, E., Zhang, D.: Properties and principles in Branciari distance space. J. Fixed Point Theory Appl. 21, Article ID 72 (2019). https://doi.org/10.1007/s11784-019-0710-2

21. Mlaiki, N., Abodayeh, K., Aydi, H., Abdeljawad, T., Abuloha, M.: Rectangular metric-like type spaces and related fixed points. J. Math. 2018, Article ID 3581768 (2018). https://doi.org/10.1155/2018/3581768

22. Kadelburg, Z., Radenović, S.: Boyd-Wong and Meir-Keeler type theorems in generalized metric spaces. J. Adv. Math. Stud. 9(1), 83-93 (2016)

23. Mitrović, Z., Radenović, S.: The Banach and Reich contractions in $b_{v}(s)$ - metric spaces. J. Fixed Point Theory Appl. 19(4), 3087-3095 (2017)

24. Dosenović, T., Radenović, S.: A comment on fixed point theorems of JS-quasi-contractions. Indian J. Math. 60(1), 141-152 (2018)

25. Alqahtani, B., Fulga, A., Karapinar, E.: Common fixed point results on an extended b-metric space. J. Inequal. Appl. 2018, Article ID 158 (2018)

26. Asim, M. Imdad, M., Radenović, S.: Fixed point results in extended rectangular b-metric spaces with an application. UPB Sci. Bull., Ser. A 81(2), 43-50 (2019)

27. Todorcević, V.: Harmonic Quasiconformal Mappings and Hyperbolic Type Metric. Springer, Cham (2019)

28. Kumari, P.S., Karapınar, E., Atangana, A.: A numerical schemes and comparisons for fixed point results with applications to the solutions of Volterra integral equations in dislocated extended b-metric space. Alex. Eng. J. 59(2) $815-827$ (2020)

29. Jleli, M., Samet, B.: A new generalization of the Banach contraction principle. J. Inequal. Appl. 2014, Article ID 38 (2014)

30. Li, Z., Jiang, S.: Fixed point theorems of JS-quasi-contractions. Fixed Point Theory Appl. 2016(1), Article ID 40 (2016)

31. Jeli, M., Karapınar, E., Samet, B.: Further generalizations of the Banach contraction principle. J. Inequal. Appl. 2014(1), Article ID 439 (2014) 
32. Kamran, T., Samreen, M., Ain, O.U.: A generalization of $b$-metric space and some fixed point theorems. Mathematics 5(2), Article ID 19 (2017)

33. Karapınar, E., Kumari, S., Lateef, D.: A new approach to the solution of the Fredholm integral equation via a fixed point on extended b-metric spaces. Symmetry 10(10), Article ID 512 (2018)

34. Karapınar, E., Czerwik, S., Aydi, H.: $(\alpha, \psi)$-Meir-Keeler contraction mappings in generalized $b$-metric spaces. J. Funct. Spaces 2018, Article ID 3264620 (2018)

35. Sumati Kumari, P., Boateng Ampadu, C., Nantadilok, J.: On new fixed point results in eb-metric spaces. Thai J. Math. 16, 367-378 (2018)

36. Monfared, H., Asadi, M., Azhini, M.: Coupled fixed point theorems for generalized contractions in ordered M-metric spaces, Results Fixed Point Theory Appl. 2018, Article ID 2018004 (2018). https://doi.org/10.30697/rfpta-2018-004

37. George, R., Radenovic, S., Reshma, K.P., Shukla, S.: Rectangular b-metric space and contraction principles. J. Nonlinear Sci. Appl. 8(6), 1005-1013 (2015)

38. Jiang, S., Li, Z., Damjanović, B.: A note on "Some fixed point theorems for generalized contractive mappings in complete metric spaces". Fixed Point Theory Appl. 2016(1), Article ID 62 (2016)

39. Imdad, M., Alfaqih, W.M., Khan, I.A.: Weak $\theta$-contractions and some fixed point results with applications to fractal theory. Adv. Differ. Equ. 2018(1), Article ID 439 (2018)

40. Banach, S.: Sur les operations dans les ensembles abstraits et leur applications aux equations integrales. Fundam. Math. 3, 133-181 (1922)

41. Liu, X., Chang, S., Xiao, Y., Zhao, L.C.: Existence of fixed points for $\Theta$-type contraction and $\Theta$-type Suzuki contraction in complete metric spaces. Fixed Point Theory Appl. 2016, Article ID 8 (2016)

42. Panda, S.K., Tassaddiq, A., Agarwal, R.P.: A new approach to the solution of non-linear integral equations via various $\mathcal{F}_{B_{e}}$-contractions. Symmetry 11, Article ID 206 (2019)

43. Sarma, I.R., Rao, J.M., Rao, S.S.: Contractions over generalized metric spaces. J. Nonlinear Sci. Appl. 2(3), 180-182 (2009)

44. Alqahtani, B., Fulga, A., Karapınar, E.: Non-unique fixed point results in extended $b$-metric space. Mathematics 6(5), Article ID 68 (2018). https://doi.org/10.3390/math6050068

45. Kadelburg, Z., Radenović, S.: Generalized metric spaces without Hausdorff property. Math. Sci. 8, Article ID 125 (2014)

46. Alghamdi, M.A., Gulyaz-Ozyurt, S., Karapinar, E.: A note on extended Z-contraction. Mathematics 8, Article ID 195 (2020)

47. Al-Rawashdeh, A., Ahmad, J.: Common fixed point theorems for JS-contractions. Bull. Math. Anal. Appl. 8, 12-22 (2016)

48. Ahmad, J., Al-Mazrooei, A.E., Altun, I.: Generalized $\theta$-contractive fuzzy mappings. J. Intell. Fuzzy Syst. 35, 1935-1942 (2018)

\section{Submit your manuscript to a SpringerOpen ${ }^{\circ}$ journal and benefit from:}

- Convenient online submission

- Rigorous peer review

- Open access: articles freely available online

- High visibility within the field

- Retaining the copyright to your article

Submit your next manuscript at $\boldsymbol{~ s p r i n g e r o p e n . c o m ~}$ 